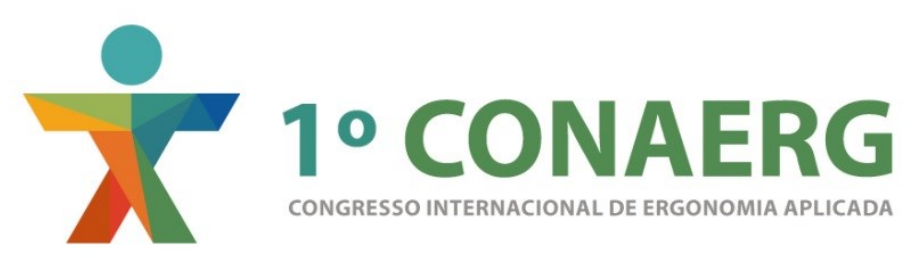

\title{
PROTÓTIPO DE UM PROCEDIMENTO CONCEITUAL PARA A AVALIAÇÃO DA QUALIDADE DE VIDA NO TRABALHO
}

\author{
Lourival Lopes Costa Filho (1); \\ Veruska Gonçalves Soares (2). \\ (1) Universidade Federal de Pernambuco | CAA | Doutor em Desenvolvimento Urbano \\ e-mail: lourivalcosta@yahoo.com \\ (2) Universidade Federal de Pernambuco | CAC | Mestranda do PPErgo \\ e-mail: veruska_ufpe@yahoo.com.br
}

\begin{abstract}
RESUMO
Este artigo visa apresentar o protótipo de um procedimento conceitual para a avaliação da Qualidade de Vida no Trabalho (QVT) em Instituições de Ensino Superior (IES) públicas, sob a ótica dos trabalhadores. A Teoria das Facetas (TF) foi adotada na formulação da estrutura metodológica proposta, que deve ser confirmada ou reformulada com base nos resultados obtidos em futuras investigações empíricas, após o exame de validação das hipóteses inicialmente consideradas.
\end{abstract}

\section{ABSTRACT}

This article aims to present a prototype for a conceptual procedure for the assessment of the Quality of Work Life (QWL) in public Higher Education Institutions (HEls) from the perspective of workers. Facet Theory (FT) was adopted in the formulation of the proposed methodological structure, which must be confirmed or reformulated on the basis of the results of future empirical research, after which a validation of the initially considered hypotheses is examined.

\section{INTRODUÇÃO}

Apesar da literatura apresentar diferentes enfoques para a expressão Qualidade de Vida no Trabalho (QVT), segundo Fernandes (1996), o principal conceito abordado pelos autores se relaciona aos interesses dos indivíduos e das organizações.

Sob esse prisma, o conceito que orienta o enfoque de QVT se apoia em duas dimensões interdependentes: (1) sob a ótica das organizações, como preceito de gestão organizacional que se expressa por um conjunto de normas, diretrizes e práticas no âmbito das condições da organização e das relações socioprofissionais de trabalho, que visa à promoção do bemestar individual e coletivo, o desenvolvimento pessoal dos trabalhadores e o exercício da cidadania organizacional nos ambientes de trabalho; (2) sob a ótica dos trabalhadores, que se expressa por meio das representações globais (contexto organizacional) e específicas (situações de trabalho) que esses constroem, indicando o predomínio de experiências de bem-estar no trabalho, de reconhecimento institucional e coletivo, de possibilidade de crescimento profissional e de respeito às características individuais (FERREIRA, 2012). 
A partir do exposto, este artigo tem como objetivo apresentar o protótipo de um procedimento conceitual para a avaliação da Qualidade de Vida no Trabalho (QVT), em Instituições de Ensino Superior (IES) públicas, sob a ótica dos trabalhadores.

Para tal, recorre-se inicialmente à literatura pertinente para se fundamentar (1) vários modelos teóricos criados visando conceituar e medir a QVT; (2) que o papel da ergonomia na melhoria do bem-estar dos trabalhadores aponta na direção da QVT, adaptando o enfoque proposto tanto aos objetivos do sujeito e/ou grupo, quanto às exigências das tarefas e das situações de trabalho; (3) que a QVT tem sido apontada como um dos fatores da motivação do desempenho humano no trabalho (FERNANDES, 1996), estando, portanto, relacionada com fatores da motivação humana no ambiente de trabalho.

Apresenta-se também a Teoria das Facetas (TF) e sua aplicação na formulação da estrutura metodológica proposta para a avaliação da QVT em IES públicas, sob a ótica dos trabalhadores. A escolha deu-se pela facilidade da TF expressar suposições teóricas, ou seja, hipóteses, de tal forma que se poderá examinar empiricamente a sua validade em pesquisas futuras, haja vista que todo delineamento de facetas define uma pesquisa específica que se resume em uma sentença estruturadora, nesse caso, como protótipo de um procedimento conceitual, que será apresentado na última seção deste artigo, baseado nas categorias de Qualidade de Vida no Trabalho de Walton (1973) e na Teoria dos Dois Fatores de Herzberg (1968 apud PILATTI, 2012), que trata da motivação.

\section{QUESTÕES DE CONTEÚDO}

Esta seção aborda os principais modelos conceituais para avaliar e mesurar a QVT, assim como princípios da ergonomia e teorias da motivação, cujas interações com a tecnologia de QVT foram consideradas relevantes na formulação de um procedimento alternativo para a avaliação da Qualidade de Vida no Trabalho em IES públicas, sob a ótica dos trabalhadores.

De acordo com Chaves (2000), no desenvolvimento da noção de QVT vários modelos foram criados visando conceituá-la e medi-la. Entre eles pode-se citar os modelos desenvolvidos por Walton (que contempla as aspirações humanas), Hackman e Oldham (centrado nos aspectos do trabalho) e o modelo de Davis e Werther (estruturado a partir do projeto de cargo). No Brasil, o autor destaca o modelo de auditoria de recursos humanos desenvolvido por Fernandes (extensão e adaptação das categorias de Walton à realidade brasileira).

Walton, em seu modelo conceitual, propõe oito categorias de QVT que "avaliam aspectos como autonomia, múltiplas habilidades, mobilidade social na organização de trabalho, segurança no emprego, entre outras" (CHAVES, 2000 p. 9-10), para compor um ambiente de trabalho com qualidade. As categorias desenvolvidas por Walton (1973) são: (1) compensação justa e adequada (renda adequada, equidade interna e externa, benefícios, prêmios); (2) condições de segurança e saúde no trabalho (ambiente físico, saúde, jornada de trabalho, carga de trabalho, material, equipamento); (3) uso e desenvolvimento de capacidade (treinamento, retroinformação, identidade e significação da tarefa, autonomia, variedade de habilidades); (4) oportunidade de crescimento e segurança (possibilidade de carreira, crescimento pessoal, segurança de emprego); (5) integração social na organização (igualdade de oportunidade, relacionamento, senso comunitário); (6) constitucionalismo (direitos trabalhistas); (7) trabalho e espaço social da vida (papel balanceado do trabalho, horário); (8) relação social vida trabalho (imagem da instituição, responsabilidade social da instituição, responsabilidade pelos serviços, responsabilidade social para empregados).

Walton (1973) afirma não ser possível estabelecer-se uma relação direta entre aumento de qualidade de vida no trabalho com aumento da produtividade, ou seja, a produtividade aumenta com a melhora de determinados aspectos de QVT até certo ponto, depois decai.

O modelo de Walton, de acordo com a visão de Fernandes (1996), autora nacional muito referenciada no tema QVT, é considerado clássico, na medida em que permite a análise de 
aspectos relevantes da QVT, a fim de que os trabalhadores atinjam os níveis desejados de satisfação, com forte influência no desempenho deles.

No modelo de Hackman e Oldham (1975), a QVT é avaliada através de quatro variáveis: (1) Dimensões da tarefa (variedade de habilidades, identidade da tarefa, significado da tarefa autonomia, feedback extrínseco, feedback intrínseco, contato); (2) Estados psicológicos (significância percebida do trabalho, responsabilidade percebida pelos resultados do trabalho, conhecimento dos resultados do trabalho); (3) Resultados pessoais e de trabalho (motivação para o trabalho, qualidade no desempenho, satisfação com o trabalho, baixa rotatividade e absenteísmo); (4) Necessidades de crescimento individual (tarefas combinadas, unidade natural de formação de trabalho, relações estabelecidas com os clientes, carga vertical, feedback). No modelo, os fatores que compõem a tarefa definem os estados psicológicos que, por sua vez, determinam os resultados pessoais e de trabalho.

Davis e Werther (1983 apud CHAVES, 2000) analisam a QVT a partir dos elementos (1) Organizacionais (abordagem mecanística, fluxo de trabalho, práticas de trabalho); (2) Ambientais (habilidade e disponibilidades de empregados, expectativas sociais); Comportamentais (autonomia, variedade, identidade de tarefa, retroinformação).

O Modelo de Auditoria de Recursos Humanos desenvolvido por Fernandes (1996), ganhador do primeiro prêmio Ser Humano, concedido pela ABRH-Nacional, apresenta cinco fases para implantação do programa de QVT: (1) Sensibilização; (2) Preparação; (3) Diagnóstico; (4) Concepção e implantação do projeto; (5) Avaliação e difusão.

Baseado nas oito categorias e na lógica do instrumento de auditoria de recursos humanos, desenvolvido por Fernandes, Chaves (2000), na série monográfica "ERGONOMIA: TÓPICOS ESPECIAIS", editada por Guimarães, propõe um modelo alternativo híbrido de medição de indicadores das condições de trabalho no próprio ambiente da tarefa. $\mathrm{O}$ autor defende que a principal vantagem desse procedimento está na redução de tempo no diagnóstico e na eliminação da dispersão no ambiente de trabalho, durante o diagnóstico.

Especificamente relacionado com instituições públicas, foi identificado o modelo de Freitas e Souza (2009). Segundo os autores, o procedimento é inédito e tem o intuito de avaliar a QVT em IES públicas, sob a ótica de servidores técnico-administrativos. Ainda segundo informado, o Modelo deve ser capaz de incorporar as principais dimensões e indicadores da QVT nesse tipo de instituição, com o objetivo de determinar: (1) a QVT em IES, segundo os funcionários de todos os níveis atuantes nas diversas unidades administrativas; (2) as fraquezas/potencialidades em termos de QVT; (3) os pontos críticos e aqueles que devem ser priorizados em prol da melhoria da QVT da IES.

Esse método de mensurar QVT, na perspectiva integrativa acima exposta, tem um enfoque dividido e busca equilibrar a ótica dos trabalhadores com aquela da organização de trabalho.

Com enfoque conceitual diferente, o procedimento aqui proposto, estruturado sob a ótica dos trabalhadores, está centrado na melhoria das condições de trabalho e no aumento da participação do funcionário no processo organizacional. Nessa linha, relaciona-se com o enfoque ergonômico, uma vez que esta disciplina apregoa o trabalho adaptado ao ser humano, portanto preservando sua QVT, em que tarefas/atividades devem ser planejadas atendendo diversos aspectos da condição humana, sejam eles tanto de natureza física como cognitiva e psíquica.

A partir de lida (2005), os diversos fatores que influem no desempenho do sistema produtivo são estudados pela ergonomia, procurando reduzir as consequências nocivas sobre o trabalhador. $\mathrm{O}$ autor ainda ressalta que a ergonomia procura reduzir a fadiga, o estresse, bem como erros e acidentes, buscando proporcionar segurança, satisfação e saúde aos trabalhadores, durante o relacionamento deles com esse sistema produtivo.

Dessa maneira, percebe-se o interesse da ergonomia nos vários aspectos que envolvem o trabalho, entre outros a QVT, não só observando as diversas características do trabalhador, como também os fatores ambientais e organizacionais. Com relação a isso, Moraes e 
Mont'Alvão (2009) destacam que, independente da linha de atuação, das estratégias, bem como dos métodos utilizados, o objeto da ergonomia é o ser humano no seu trabalho trabalhando, seja realizando tarefas cotidianas, seja executando as atividades do dia-a-dia.

De acordo com a visão de Limongi-França (2012), com grande frequência tem ocorrido o alinhamento dos aspectos organizacionais e da perspectiva humana nas empresas. O lado humano, continua a autora, é levado em consideração nas organizações, aumentando-se a possibilidade de se viver melhor.

A mesma autora ainda acrescenta que cada um tem suas inquietações, no que concerne às pressões sofridas no ambiente de trabalho e na vida pessoal, ao estresse diário, aos cuidados com a saúde, à conciliação entre trabalho, família e lazer, além dos constantes impactos tecnológicos. Em decorrência disso, percebe-se o desejo de se ter bem-estar no ambiente de trabalho. As empresas, por isso, passaram a ter novas atitudes e as pessoas a se preocupar em melhorar seus estilos de vida, ampliando-se as discussões sobre qualidade de vida, que é almejada não só no trabalho, como também no cotidiano.

Nesse contexto de mudanças, a gestão da QVT vem se tornando uma preocupação cada vez mais presente nas organizações, com o intuito de preservar a saúde de seus colaboradores, além de garantir o bem-estar e elevar o nível de motivação no ambiente de trabalho (MUSSENGUE; LIMONGI-FRANÇA, 2010).

Cumpre destacar que as organizações contemporâneas buscam por profissionais cada vez mais produtivos e qualificados, tornando a competitividade acirrada, bem como ampliando a cobrança sobre os trabalhadores, para atingirem metas e resultados mais expressivos, aumentando a necessidade de se investir em qualificação profissional. Nessa conjuntura, percebe-se a presença cada vez mais expressiva da valorização do capital humano e do nível de conhecimento (OLIVEIRA; LIMONGI-FRANÇA; MURITIBA, 2002).

A partir desses autores, tem-se como diferencial dessas organizações a apreciação de recursos significativos, tais como: o conhecimento e a inovação, uma vez que, para permanecerem competitivas no mercado, os talentos, as ideias e as iniciativas dos seus colaboradores devem ser considerados.

A necessidade da criação pelos gestores de um ambiente de trabalho que atraia pessoas de grande talento, e que elas sintam vontade de permanecer, tendo inspiração para criação e desenvolvimento de novos projetos é um fator enfatizado por Bateman e Snell (2009), sendo o uso do intelecto dos trabalhadores aplicado como forma de gerar lucro para a instituição.

Ao importar ações da iniciativa privada, o serviço público também procura alcançar melhoria, salientando que "a investidura em cargo ou emprego público depende de aprovação prévia em concurso público de provas ou de provas e títulos [...]", conforme preceitua o Art. 37, inciso II da Constituição Federal (BRASIL, 1988). Logo, o candidato deve ter a qualificação mínima exigida no edital para que possa assumir o cargo, caso seja classificado no certame.

Ao abordar os modelos e fatores determinantes de QVT, Fernandes (1996) inicia seus estudos com os autores clássicos Maslow e Herzberg, que se dedicaram aos fatores motivacionais relacionados às necessidades humanas, refletindo não só no desempenho como também na autorrealização do indivíduo.

Maslow (1954 apud KOTLER, 1998) organiza as necessidades humanas em uma hierarquia, que, em ordem de importância, são: necessidades fisiológicas (comida, água, abrigo); de segurança (defesa, proteção); sociais (sentimento de posse, amor), de estima (autoestima, reconhecimento, status); de autorrealização (desenvolvimento pessoal e conquista). A princípio, tenta-se satisfazer as necessidades mais urgentes, que se encontram na base hierárquica e assim sucessivamente, ou seja, na proporção que cada necessidade importante for satisfeita, a próxima necessidade mais importante irá ocorrer.

Com relação à Teoria dos Dois Fatores desenvolvida por Herzberg (1968 apud PILATTI, 2012), tem-se os fatores de manutenção ou higiênicos e os fatores motivadores. 
O autor acrescenta que Herzberg usava o termo enriquecimento do trabalho ao investigar sobre fatores geradores de satisfação e insatisfação no trabalho. De acordo com a visão de Pilatti (2012), Herzberg, em seus estudos, destaca que fatores referentes ao conteúdo do cargo ou à natureza das tarefas desempenhadas pelo indivíduo são fatores de satisfação ou motivadores, já que os estabelecidos pelo ambiente que permeiam a pessoa, e relacionados às condições entre as quais desenvolve seu trabalho são fatores que somente previnem a insatisfação, ou seja, de manutenção ou higiênicos.

O autor acima citado ressalta que Herzberg, ao conceituar motivação, distinguiu os fatores motivadores dos fatores de manutenção. Os motivadores (realização, reconhecimento, responsabilidade, ascensão, desenvolvimento, etc.) são intrínsecos ao indivíduo, pois exigem um esforço próprio para execução das tarefas. Já os fatores de manutenção são extrínsecos ao indivíduo, por tratar dos recursos oferecidos ao trabalhador para o desempenho de suas atribuições, tais como: condições de trabalho, salário, segurança, contexto, benefícios, política institucional.

A percepção do trabalhador dos pontos favoráveis e desfavoráveis em seu ambiente de trabalho gera a ideia de QVT, que tem forte ligação com a motivação, sendo a Teoria dos Dois Fatores muito interessante por elencar subsídios efetivos que ocasionam satisfação e insatisfação (PILATTI, 2012).

Segundo Conte (2003), com Qualidade de Vida no Trabalho as pessoas são mais felizes, consequentemente, elas vão produzir mais. Sendo assim, melhorando a QVT, os gestores podem conseguir motivar os funcionários que, presumivelmente, podem produzir mais por estarem satisfeitos, atender melhor às expectativas dos clientes e, em decorrência disso, obter resultados melhores para a organização.

De acordo com Moraes e Mont'Alvão (2009), ao se atender aos requisitos ergonômicos é possível não só maximizar o conforto, a satisfação e o bem-estar, como também minimizar constrangimentos, custos humanos e carga cognitiva, psíquica e física do trabalhador; além de otimizar o desempenho da tarefa, o rendimento do trabalho, bem como a produtividade do sistema humano-máquina.

$O$ atendimento de requisitos ergonômicos pelas instituições pode contribuir para a promoção da Qualidade de Vida no Trabalho, tornando possível que os trabalhadores se sintam bem e motivados. Essas interações podem demonstrar a forte inter-relação da QVT com os princípios ergonômicos e os fatores motivacionais.

\section{QUESTÕES TEÓRICO-METODOLÓGICAS}

A Teoria das Facetas (TF), criada por Louis Guttman durante os anos 50 e, originalmente, publicada no artigo "A Faceted Definition of Intelligence" em 1965, foi adotada na formulação da estrutura metodológica proposta.

A TF não se trata de uma metodologia, mas de um procedimento metodológico metateórico que auxilia o equilíbrio do nível teórico com o nível empírico da pesquisa, na definição com mais precisão dos elementos de coleta de dados e na determinação de como os dados devem ser analisados. Essa etapa consiste em definir hipóteses, encontrar as facetas do modelo teórico e estabelecer os elementos que as constituem (SHYE; ELIZUR; HOFFMAN, 1994; BILSKY, 2003). Cada faceta representa uma categoria conceitual, composta por subcategorias de elementos a serem testados (COSTA FILHO, 2014).

Em síntese, Bilsky (2003) diferencia três tipos de facetas. O primeiro tipo faz referência à população dos sujeitos da pesquisa (background). O segundo tipo relaciona-se ao conteúdo das variáveis pesquisadas (conteúdo). Ressalta-se que, juntas, as facetas de população e conteúdo determinam o campo de interesse da pesquisa (domínio). E, finalmente, o terceiro tipo de faceta diz respeito ao universo das reações ou respostas dos sujeitos pesquisados, 
sendo nomeado como amplitude de respostas admissíveis, habitualmente apresentadas como uma escala ordenada de aceitação (racional).

De acordo com o autor acima citado, todo delineamento de facetas determina uma pesquisa específica, descritiva ou experimental, podendo resumir-se em uma sentença estruturadora. Tal sentença, não só menciona as diferentes facetas de interesse científico de modo aditivo, como também especifica suas relações mútuas, usando elos. As sentenças estruturadoras são lidas da esquerda para a direita, aplicando de cada vez um elemento interno de cada faceta, assim, produzirá quantas diferentes combinações existam entre os elementos pertencentes ao campo de interesse.

É oportuno, agora, abordar a aplicação da Teoria das Facetas no procedimento proposto. A Tabela 1 apresenta a sentença estruturadora para a avaliação da QVT em IES públicas, sob a ótica dos trabalhadores, assim como os nomes das facetas de conteúdo e seus elementos internos. O primeiro tipo de faceta refere-se à população amostral que se pretende abordar (background). O segundo tipo contempla o conteúdo das variáveis pesquisadas e, juntamente com a faceta de background, estabelece o domínio da pesquisa. O terceiro tipo representa o universo de respostas possíveis (racional) em relação ao domínio da pesquisa.

Tabela 1 | Sentença estruturadora para a avaliação da QVT em IES públicas

\begin{tabular}{ll}
\hline Em que medida a pessoa x (servidores da IES pública) avalia que & \\
\hline FACETA A & $\begin{array}{l}\text { FACETA B } \\
\text { (fatores da motivação) }\end{array}$ \\
$\begin{array}{l}\text { A1 - a compensação pelo seu trabalho } \\
\text { A2 - as condições de trabalho }\end{array}$ & \\
A3 - o uso/desempenhico de capacidades & \\
A4 - a oportunidade de crescimento e segurança & relacionada c/ um fator \\
A5 - a integração social na organização & \\
A6 - o constitucionalismo & \\
A7 - o trabalho e espaço social & B2- motivador \\
A8 - a relevância social & \\
\hline
\end{tabular}

\section{RACIONAL}

(1) nunca

(2) pouco

(3) mais ou menos

(4) muito

(5) muitíssimo

no ambiente de trabalho em que você está lotado?

Fonte: autores do artigo com base nos dados da pesquisa realizada

A população amostral abordada em uma futura investigação empírica relacionada com a avaliação da QVT seria composta por diferentes grupos de servidores de uma IES pública.

As duas facetas de conteúdo, relacionadas com a QVT e a Motivação, foram consideradas hipoteticamente determinantes para a avaliação pretendida. A FACETA A - categorias conceituais da QVT - está relacionada com as oito categorias do modelo de QVT de Walton (1973), quais sejam: (A1) a compensação pelo seu trabalho; (A2) as condições de trabalho; (A3) o uso/desempenho de capacidades; (A4) a oportunidade de crescimento e segurança; (A5) a integração social na organização; (A6) o constitucionalismo; (A7) o trabalho e espaço social; (A8) a relevância social. A FACETA B - fatores da motivação - refere-se à forma em que as categorias da QVT são relacionadas com esses fatores, considerando a rotina diária de trabalho e a vida pessoal dos trabalhadores. Com relação à Teoria dos Dois Fatores desenvolvida por Herzberg (1968 apud PILATTI, 2012), tem-se: (B1) fatores higiênicos e (B2) fatores motivadores. 
Foi considerada uma escala de cinco opções para a avaliação da QVT pelos servidores de IES públicas abordados. 5 é o ponto máximo de importância e 1 é o ponto mínimo, sendo 3 o ponto intermediário: (1) nada; (2) pouco; (3) mais ou menos; (4) muito; (5) muitíssimo.

Com base na sentença estruturadora para a avaliação da QVT, em IES públicas (Tabela 1), as combinações dos elementos das facetas de conteúdo - categorias conceituais da QVT e fatores da motivação - encontram-se 16 diferentes conjuntos (A8 x B2) ou observações a serem consideradas em uma futura investigação empírica.

A sentença estruturadora proposta para avaliação da QVT, em IES públicas, como uma referência inicial da pesquisa, é analisada em relação aos resultados empíricos que devem confirmar ou reformular as hipóteses inicialmente estabelecidas. Assim, após os dados serem analisados, têm-se informações suficientes para a construção ou não de uma nova sentença, a ser estruturada como uma consequência direta dos resultados empíricos.

\section{QUESTÕES METODOLÓGICAS}

Admite-se que a pesquisa de campo do tipo exploratória, fazendo uso de entrevistas com roteiro estruturado (MARCONI; LAKATOS, 2009), seja uma técnica válida para a avaliação que servidores de IES públicas têm da QVT, em seus ambientes de trabalho e, nesse sentido, parte-se agora para a apresentação do conjunto de questões.

A geração desse conjunto de questões, entretanto, precisa estar diretamente associada às variáveis consideradas, todas listadas na sentença estruturadora para a avaliação da QVT em IES públicas (Tabela 1), que estabelece precisamente a relação entre todas as partes envolvidas, ou seja, o que se pretende avaliar, os referentes da experiência, bem como o racional para as possíveis respostas.

Tal sentença, conforme dito antes, determina 16 diferentes conjuntos ( $\mathrm{A} 8 \times \mathrm{B} 2$ ). $\mathrm{O}$ número de elementos de estímulos para as entrevistas, por conseguinte, deve totalizar 16 questões relacionadas com categorias conceituais da QVT e fatores da motivação, expressando o modo como os elementos que definem a investigação se relacionam (Quadro 1).

Quadro 1: Roteiro estruturado para as entrevistas

\begin{tabular}{|c|l|l|}
\hline Facetas & $\mathbf{N}^{\mathbf{0}}$ & Questões \\
\hline A1B1 & 01 & O seu salário é suficiente para o seu sustento e permite acompanhar/sair com amigos/familiares? \\
\hline A1B2 & 02 & A sua remuneração é condizente com as suas responsabilidades? \\
\hline A2B1 & 03 & Você tem disponibilidade de materiais e equipamentos para desenvolver suas atribuições? \\
\hline A2B2 & 04 & O ambiente físico é estimulante para o desempenho do seu trabalho? \\
\hline A3B1 & 05 & Existe uma interação para realizar o planejamento da rotina de trabalho do seu setor? \\
\hline A3B2 & 06 & Você tem oportunidade de aplicar seus conhecimentos e desenvolver suas habilidades com autonomia? \\
\hline A4B1 & 07 & Você tem sua remuneração assegurada? \\
\hline A4B2 & 08 & Existe preocupação com a melhoria contínua dos servidores e oportunidade de crescimento profissional? \\
\hline A5B1 & 09 & Há tratamento igualitário entre gestores e subordinados? \\
\hline A5B2 & 10 & Você tem reconhecimento de gestores/colegas pelo trabalho que desempenha? \\
\hline A6B1 & 11 & Há igualdade de remuneração, recompensas simbólicas e segurança no trabalho? \\
\hline A6B2 & 12 & Existe uma divulgação de seus direitos e deveres? \\
\hline A7B1 & 13 & A sua jornada de trabalho é compatível com a sua vida pessoal? \\
\hline A7B2 & 14 & Você consegue equilibrar o seu tempo entre trabalho, família, amigos e lazer? \\
\hline A8B1 & 15 & A IES tem uma boa imagem interna? \\
\hline A8B2 & 16 & A IES tem imagem de credibilidade externa? \\
\hline
\end{tabular}

Fonte: autores do artigo com base nos dados da pesquisa realizada 


\section{CONCLUSÃO}

Pelo que se propõe, espera-se que as contribuições deste artigo possam aprimorar, no que for possível, os aportes teórico-conceituais relacionados com o objeto estudado, ampliando sua abrangência analítica, bem como favorecer a avaliação da QVT em IES públicas, para a melhoria do ambiente de trabalho e a satisfação dos servidores.

O protótipo do procedimento conceitual para a avaliação da QVT, em IES públicas, deve ser confirmado ou reformulado em futuras investigações empíricas, quando poderá ser examinada a validação das hipóteses inicialmente consideradas, assim como revelar a consistência do protótipo proposto.

Espera-se, ainda, que os gestores das IES Públicas possam utilizar de forma satisfatória o protótipo aqui presentado, com o propósito de aperfeiçoar o gerenciamento dos processos organizacionais. Nessa perspectiva, a abordagem proposta poderá, ainda, contribuir para a melhoria da Qualidade de Vida no Trabalho dos servidores.

\section{REFERÊNCIAS}

BATEMAN, Thomas S.; SNELL, Scott A.. Administração: novo cenário competitivo. Tradução: Bazán Tecnologia e Linguística Ltda. Revisão Técnica José Ernesto Lima Gonçalves. 2a. ed. 2a. reimpr. São Paulo: Atlas, 2009.

BILSKY, Wolfgang. A Teoria das Facetas: noções básicas. In Estudos de Psicologia, v.8, n.3, 2003. p. 357-365.

BRASIL. Constituição da República Federativa do Brasil de 1988. Disponível em: $<$ <ttp://www.planalto.gov.br/ccivil_03/constituicao/constituicaocompilado.htm>. Acesso em: 02 abr. 2015.

CHAVES, Luiz Fernando Nicodemo. Qualidade de Vida no Trabalho (QVT): antecedentes, definições e modelos teóricos. In: GUIMARÃES, Lia Buarque de Macedo (Ed.). Ergonomia: tópicos especiais. 2. ed. Porto Alegre: Universidade Federal do Rio Grande do Sul, Escola de Engenharia, Programa de Pós-Graduação em Engenharia de Produção, 2000. Cap. 1. p. 1-50. (Série Monográfica Ergonomia).

CONTE, Antônio Lázaro. Qualidade de Vida no Trabalho. Revista FAE Business, Curitiba, n. 7, p.32-34, nov. 2003. Disponível em: <http://www.unifae.br/publicacoes/pdf/revista_fae_business/n7/ rev_fae_business_07_2003_gestao_10.pdf>. Acesso em: 02 abr. 2015.

COSTA FILHO, Lourival Lopes. O Enfoque da Teoria das Facetas na Avaliação de Lugares. In: MONT'ALVÃO, C.; VILLAROUCO, Vilma (Orgs.), Um Novo Olhar para o Projeto 2: a ergonomia no ambiente construído. Recife: Editora UFPE, 2014. p.11-26.

FERNANDES, Eda Conte. Qualidade de Vida no Trabalho: como medir para melhorar. 3a. ed. Salvador: Casa da Qualidade, 1996.

FERREIRA, Mário César. A Ergonomia da Atividade se Interessa pela Qualidade de Vida no Trabalho? Reflexões Empíricas e Teóricas. In: Cadernos de Psicologia Social do Trabalho, 2008, vol. 11, n. 1, pp. 83-99. Disponível em <http://ergopublic.com.br/arquivos/1252860601.97-arquivo.pdf> Acesso em 24 junho 2016.

FREITAS, André Luís Policani; SOUZA, Rennata Guarino Bastosde. Um modelo para avaliação da qualidade de vida no trabalho em universidades públicas. Sistemas e Gestão, v. 4, n. 2, p. 136-154, 2009. Disponível em: <http://www.revistasg.uff.br/index.php/sg/article/view/V4N2A4/V4N2A4> Acesso em: 22 out. 2015.

HACKMAN, Richard; OLDHAM, Greg R.. Development of the Job Diagnostic Survey. Journal of Applied Psychology, v. 60, n. 2, p. 159-170, 1975.

IIDA, Itiro. Ergonomia: projeto e produção. São Paulo: Edgard Blücher, 2005.

INTERNATIONAL ERGONOMICS ASSOCIATION (IEA). What is ergonomics? IEA, 2015. Disponível em: <http://www.iea.cc/whats/index.html>. Acesso em: 03 abr. 2015. 
KOTLER, Philip. Administração de Marketing: análise, planejamento, implementação e controle. 5. ed. São Paulo: Atlas, 1998. Tradução de: Ailton Bomfim Brandão.

LIMONGI-FRANÇA, Ana Cristina. Qualidade de Vida no Trabalho - QVT: conceitos e práticas nas empresas da sociedade pós-industrial. 2. ed. 8. reimpr. São Paulo: Atlas, 2012.

MARCONI, Marina de Andrade; LAKATOS, Eva Maria. Técnicas de pesquisa: planejamento e execução de pesquisas, amostragens e técnicas de pesquisa, elaboração, análise e interpretação de dados. 7. ed. 2. reimpr. São Paulo: Atlas, 2009.

MORAES, Ana Maria de; MONT'ALVÃO, Cláudia. Ergonomia: Conceitos e Aplicações. Rio de Janeiro: 2AB, 2009 (4a. edição, ampliada).

MUSSENGUE, Mafalda Melta Augusto; LIMONGI-FRANÇA, Ana Cristina. A Gestão de pessoas no Ministério da Ciência e Tecnologia de Moçambique: desafios estratégicos. Revista de Administração, Contabilidade e Economia da Fundace, Ribeirão Preto, n. 1, p.1-20, set. 2010. Disponível em: <http://fundace.org.br/revistaracef/index.php/racef/article/view/16/11>. Acesso em: 31 jul. 2015.

OLIVEIRA, Patrícia Morilha de; LIMONGI-FRANÇA, Ana Cristina; MURITIBA, Sérgio Nunes. Avaliação de Resultados em $\mathrm{RH}$ : fontes de evidência da percepção e das práticas dos administradores no caso dos programas de Qualidade de Vida no Trabalho. In: ENCONTRO ANUAL DA ASSOCIAÇÃO NACIONAL DOS PROGRAMAS DE PÓS-GRADUAÇÃO EM ADMINISTRAÇÃO, 2002, Salvador. Anais... Salvador: ANPAD, 2002. p. 1 - 15.

PILATTI, Luiz Alberto. Qualidade de Vida no Trabalho e teoria dos dois fatores de Herzberg: possibilidades-limite das organizações. Revista Brasileira de Qualidade de Vida, v. 4, n. 1, jan./jun.2012. Disponível em: <https://periodicos.utfpr.edu.br/rbqv/article/view/1195/801>. Acesso em: 18 jul. 2015.

SHYE, Samuel; ELIZUR, Dov; HOFFMAN, Michael. Introduction to Facet Theory: content design and intrinsic data analysis in behavioral research. London: Sage Publications, 1994.

WALTON, Richard E.. Quality of Working Life: What is it? Sloan Management Review, Harvard University, v. 15, n. 1, p.11-21, Fall, 1973. 